\title{
The Impact of FDI in Retail on SMEs Sector with Special Reference to Malappuram District
}

\author{
Aslam Muhammed Yaseen.C.K ${ }^{1}$ \\ Sreejith.P $P^{2}$ \\ ${ }^{1+2}$ Majlis Arts and Science College, Valanchery, India \\ Correspondence: Aslam Muhammed Yaseen.C.K, Majlis Arts and Science College, Valanchery, India, E-mail: \\ aslammohdyaseen@gmail.com
}

Received: September 1, 2017

Accepted: September 15, 2017

Online Published: September 25, 2017

\begin{abstract}
A fairly liberal foreign direct investment policy is the path for any country to globalization and through that to a world class development. An economy should be flexible enough to welcome international business players to invest high in that economy. Entrance of international brands to a country improves the health of an economy and it also increases the standard of living in that country. Even though India resisted FDI earlier, later realized it's a necessity in the effort of becoming a developed country. When India liberalized their FDI policies in 1990s, most had a concern that whether it will affect our domestic businesses. Even though there are Indian companies who failed to compete with foreign ones, totally our liberalized FDI has been giving a win-win result till now. But, it is clear that Globalization has changed the face of our economy and the style of doing business in it. One of the area which Globalization had most influence was unarguably Small and Medium scale enterprises (SMEs). Growth of organized retailing and E-commerce has made both positive and negative effects on SMEs. For last 3 years, there have been several vital changes in FDI policy of India which liberalized the terms even more. We can expect the waves of those changes hitting the shore soon. In this current developing scenario, it is important to forecast the effects of those policies in our economy.In this article, the author investigates on the attitude of small and medium entrepreneurs on our new FDI policies.
\end{abstract}

Keywords: Development, FDI policies, Globalisation, Government policies, Indian economy, SMEs.

\section{Introduction}

India is now the last major frontier for globalized retail. In the twenty years since the economic liberalization of 1991, India's middle class has greatly expanded, and so has its purchasing power. But over the years, unlike other major emerging economies, India has been slow to open its retail sector to foreign investment. Recent signals from the government however suggest that this may be about to change: global supermarket chain stores such as Wal-Mart (United States), Carrefour (France), Marks \& Spencer and Tesco (United Kingdom), and Shoprite (South Africa) may finally be allowed to set up shop in India. Foreign direct investment (FDI) in the retail sector in India is restricted. In 2006, the government eased retail policy for the first time, allowing up to 51 per cent FDI 
through the single-brand retail route. Since then, there has been a steady increase in FDI in the retail sector, and the cumulative FDI in single-brand retail stood at $\$ 195$ million by the middle of 2010 (DIPP, 2010). Foreign investment in the single-brand retail sector in India has been resilient to the global economic crisis of 2007-08. Given India's large population and rapidly expanding middle-class, there is robust and growing demand and a rapidly expanding market.

\section{Literature Review}

Anuradha.A and Prabhu.R in their study named "Fine-tuning the retail sector in India and the preconditions for FDI in retailing" says that, unlike in BPO industry where the work will be done by Indians and profit will go to the foreigners FDI multi-branded retail should favour both the parties, the home country's economy and the foreign country's economy. As we are in the early days for multi branded retail, it is unlikely that any investors would be in a hurry to declare their investment in the economy till the dust settles down except for a very few players like wal mart and carrefour.

Bhattacharyya Jita, Bhattacharyya Mousumi (2012), "Impact of Foreign Direct Investment and Merchandise and Services Trade of the Economic growth in India: an Empirical study", the study revealed that there was a long term relationship between FDI, merchandise, service trade and economic growth of India. Bi-directional causality is observed between merchandise trade and economic growth, services trade and economic growth. Unidirectional causality is observed from FDI to economic growth and FDI to merchandise trade. A unidirectional causality is also observed from merchandise trade to services trade.

Abdul A.,Morris R. (2011), "Ease of doing business and FDI inflow to Sub-Saharan Africa and Asian countries" The study found that two factors, "registering property" and "trading across borders", were found to be related to FDI over all six years of the study (2000-2005) for the combined sample. Also, several factors were found to be related to FDI received by SSA and Asian countries during various years.

Singh S., Singh M.(2011), "Trends and prospects of FDI in India” This study investigates the trend of FDI inflow to India, during 1970-2007 using time series data. This paper aims to study the reasons behind the fluctuations of the FDI inflow in India and to search the cause that is responsible for the fluctuations of the trends of FDI.

Singh Y., Bhatnagar A. (2011), "FDI in India and China; A comparative analysis" The study found that both enjoys healthy rates of economic growth but FDI inflow in china is higher than India.

\subsection{India Retail Reforms with FDI}

Until 2011, Indian central government denied foreign direct investment (FDI) in multi-brand Indian retail, forbidding foreign groups from any ownership in supermarkets, convenience stores or any retail outlets, to sell multiple products from different brands directly to Indian consumers.

The government of Manmohan Singh, prime minister, announced on 24 November 2011 the following:

-India will allow foreign groups to own up to 51 per cent in "multi-brand retailers", as supermarkets are known in India, in the most radical pro-liberalisation reform passed by an Indian cabinet in years;

-Single brand retailers, such as Apple and IKEA, can own 100 percent of their Indian stores, up from the previous cap of 51 percent;

-Both multi-brand and single brand stores in India will have to source nearly a third of their goods from small and medium-sized Indian suppliers;

-All multi-brand and single brand stores in India must confine their operations to 53odd cities with a population over one million, out of some 7935 towns and cities in India. It is expected that these stores will now have full 
access to over 200 million urban consumers in India;

-Multi-brand retailers must have a minimum investment of US\$100 million with at least half of the amount invested in back end infrastructure, including cold chains, refrigeration, transportation, packing, sorting and processing to considerably reduce the post harvest losses and bring remunerative prices to farmers;

-The opening of retail competition will be within India's federal structure of government. In other words, the policy is an enabling legal framework for India. The states of India have the prerogative to accept it and implement it, or they can decide to not implement it if they so choose. Actual implementation of policy will be within the parameters of state laws and regulations. The opening of retail industry to global competition is expected to spur a retail rush to India. It has the potential to transform not only the retailing landscape but also the nation's ailing infrastructure.

\subsection{Strong growth in the Indian Retail Industry}

The retail sector in India is emerging as one of the largest sectors in the economy. By 2015, the total market size is estimated to be around US\$ 600 billion, thereby registering a CAGR of 7.45 per cent since 2000. Retail industry is expected to grow to US\$1.3 trillion by 2020, registering a CAGR of 9.7 per cent between 2000-2020.

\section{Research Methodology}

The research is conducted on a sample of 30 small, medium enterprises from different regions of the Malappuram district, Kerala, India. The researcher used structured Questionnaires to collect primary data from entrepreneurs. Secondary data is collected from various Journals, and websites.

\section{Research Objectives}

- To study about the impact of FDI on SME sector in Malappuram district

- To know the attitude of Small and medium scale entrepreneurs towards FDI

\section{Analysis and Interpretation}

\subsection{Are you in favour of government's decision to allow 51 \% FDI in retail?}

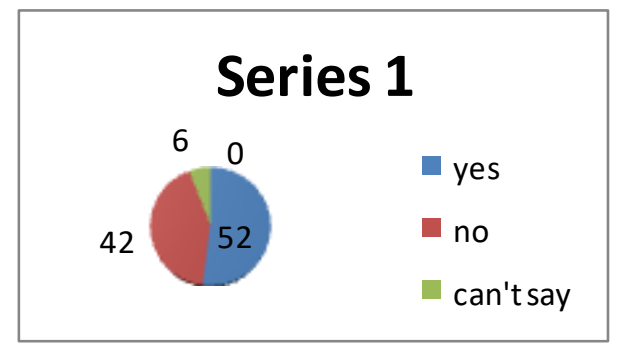

\section{Interpretation}

The SME Industry, according to the survey, is in favour of the government's decision to allow $51 \%$ Foreign Direct Investment (FDI) in multi-brand retail and $100 \%$ in single brand retail. A majority of the SME companies, surveyed have supported the government's decision and the notification allowing 100\% FDI in single brand retail and about 52 percent of respondents also expect earlier and speedier implementation of 51\%FDI in multi-brand retail. 


\subsection{How the SME industries consider entry of MNC retailers as a threat or opportunity?}

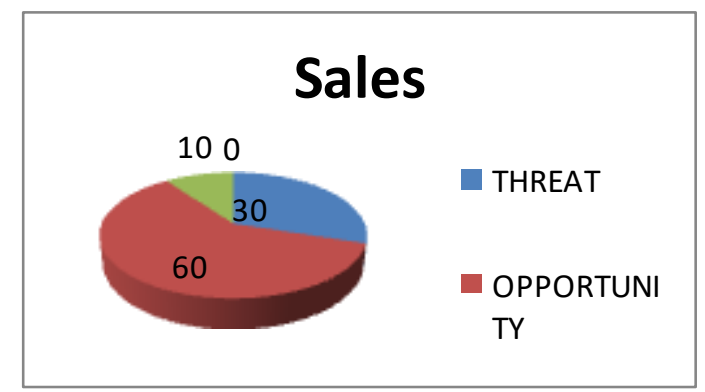

\section{Interpretation}

On the question how the SME industry consider entry of MNC retailers as a threat or opportunity, majority of respondents (60\%) see it as an opportunity for their sector while around $30 \%$ of respondents perceive it as a threat. About 10 percent of respondents are of the opinion that the decision would have little or no impact on their company

\subsection{Growth in the sales of product}

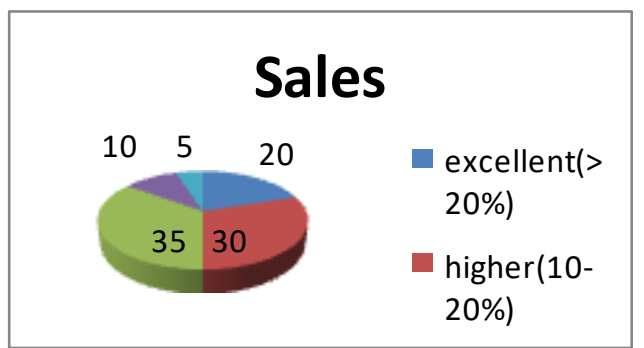

\section{Interpretation}

Majority of the respondents (98 percent) are of the opinion that the opening of the FDI in retail will augment growth of sales of their products. Of them, around 20 percent respondents foresee the growth of sales of their products to escalate in the excellent range of more than 20 percent , 30 percent of the respondents expect the impact on growth of sales to be in the high range of 10-20 percent while 35 percent expect it to be in moderate range 5-10 percent. 10 percent of the respondents perceive the growth to remain in a low range (0-5) category and 5percent of the respondents feel that the decision would have a negative impact on the growth of sales of their products.

\subsection{Growth in the size of the company}

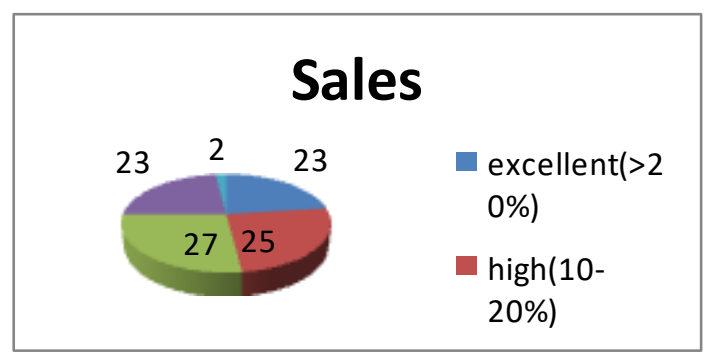

\section{Interpretation:}

On the aspect of the possible impact on the size of the industry, business and capacity addition, majority of the 
respondents (98 percent) expect the size of their company to grow with the opening of 51 percent FDI in multi-brand retail along with 100 percent FDI in single-brand retail. Around 23 percent of respondents perceived that their industry would grow by excellent rate of more than 20 percent). 25 percent of the respondents expect the impact on the size or capacity addition to be in the high range of 10-20 percent while 27 percent expects the growth to be in the moderate range of 5-10percent and 23 percent perceive the growth to being the low range (0-5 percent) category. A significantly negligible 2 percent of the respondents feel that the decision would have a negative impact on the growth of size of the industry and business.

\subsection{New Orders/ Contract}

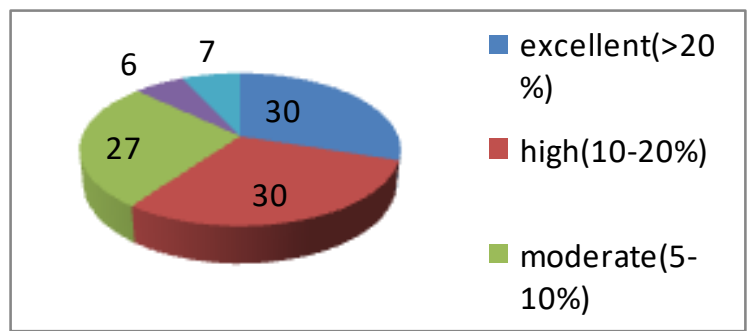

\section{Interpretation:}

Majority of respondents are of the view that the decision of opening of the FDI in retail would impact positively in the form of new orders/contracts generated. Around 30 percent of respondents expect the new orders and contract to grow substantially with more than excellent rate of 20 percent) of growth. 27 percent of the respondents expect the impact on the new orders and contracts to be in the high range of(10-20 percent) while 30 percent expect the growth of orders / contracts in respect of their products to be in the moderate range (5-10 percent). Around 6 percent perceive the growth to be in a low range (0-5) category but 2 percent of the respondents feel that the decision would have a negative impact on the growth of size of the industry in terms of new orders

5.6 Qualitative improvements and branding of the products

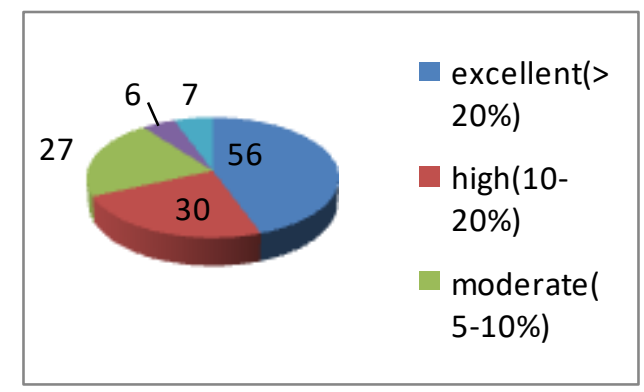

\section{Interpretation:}

Over 56 percent of the respondents are also of the view that the government's decision of mandatory sourcing of a minimum of $30 \%$ from Indian micro and small industry will help in achieving qualitative improvements and branding of the products. This in turn will ensure SMEs in receiving a sure source of market for their products which ensuring higher prices for their products/supplies. This will also provide for expansion of the scales of production facilitating domestic value addition in manufacturing, thereby creating a multiplier effect on employment, technology up gradation and income generation, demand and further investment. 


\subsection{Supply chain efficiencies}

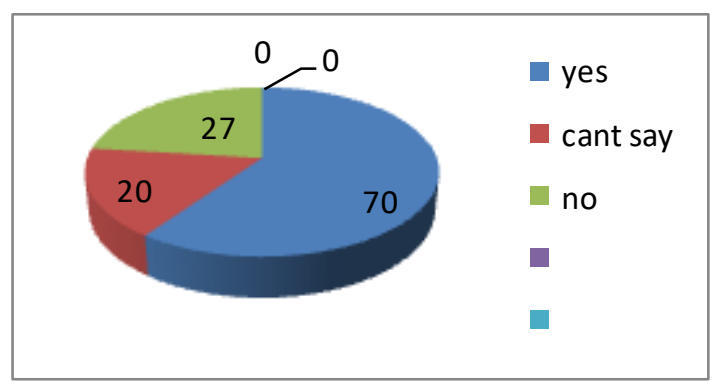

\section{Interpretation:}

70 percent of the respondents are of the opinion that the opening up of the retail would lead to improvements in the supply chain efficiencies in their sector. This will in turn integrate small and medium size enterprises into the modern trade process while reaping benefits of different economies of scale and growing healthily with mutual dependence on each other. As a result, a substantial amount of knowledge and skills transfer would take place in the sector

\subsection{Employment}

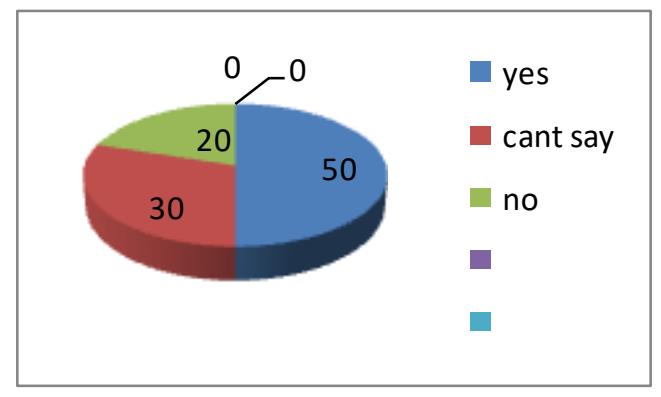

\section{Interpretation:}

With regard to employment, around 50 percent of the respondents are of the opinion that the decision would have a positive impact on their employment whereas 30 percent expect no substantial change in the employment in this sector with opening up of FDI in retail. Around 20 percent expect the impact on the employment to be negative in this sector.

\section{Findings}

- Majority of the respondents are of the opinion that the opening of the FDI in retail will result in substantial growth of sales of their products.

- On the aspect of the possible impact on the size of the industry, business and capacity addition, majority of the respondents expect the size of their Industry / company to grow with the opening of 51 percent FDI in multi-brand retail along with 100 percent FDI in single-brand retail.

- Majority of respondents are of the view that the decision of opening of the FDI in retail would impact positively in the form of new orders/ contracts generated

- Over 56 percent of the respondents are also of the view that the government's decision of mandatory sourcing of a minimum of $30 \%$ from Indian micro and small industry will help in achieving qualitative improvements and branding of the products 
- Majority of the respondents are of the opinion that the opening up of the retail would lead to improvements in the supply chain efficiencies in their sector which in turn will integrate small and medium size enterprises into the modern trade process, resulting in substantial amount of knowledge and skills transfer in the sector.

- Around 50 percent of the respondents are of the opinion that the decision would have a positive impact on their employment whereas 30 percent expect no change in the employment scenario. Around 20 percent expect the impact of FDI in retail on the employment in the SME sector to be negative.

\section{Conclusion}

Till recently, Government of India allowed 51\%FDI in single brand retail and 100\% in cash \& carry only. But FDI in multi brand retail has not yet been allowed. One of the major steps taken by the Government recently to encourage the organized retailing in the country was the recent decision of the cabinet to allow 51\% FDI in multi brand retail and 100\% in single brand retail in Nov 2011.In view of the above background, the researcher undertaken a study on Foreign Direct Investment (FDI) in retail on SME sector,The research has also tried to find out and make an assessment of the impact of the opening of FDI in retail on SME in terms of different growth indicators / parameters like sales, size of the industry / capacity expansion, employment, branding and achieving other efficiencies. On the question how the SME industry consider entry of MNC retailers as a threat or opportunity, majority of respondents $(66.7 \%)$ see it as an opportunity for their sector .

\section{References}

Anuradha.A, Prabhu.R, (2014).Fine-tuningtheretailsectorinIndiaandthepreconditionsforFDIinretailing. IOSR journal of humanities and social science. 19(1).71-77

Baskaran A (2010), “The Impact of Foreign Direct Investment on Indian Economy”, Excel Books.

Direct Tax Laws (2010), “Guide To Foreign Direct Investments In India With FDI Policy Issued on 1st April 2010”, Taxmann Publications Pvt. Ltd.

G. Gopala Krishna Murthy (2007), "Foreign Institutional Investors - Indian and Global Scenario", Icfai University Press, Hyderabad

H. S. Kehal (2005), "Foreign Investments in Developing Countries”, Palgrave Macmillan, New York

Jack L. Treynor (2007), "Treynor on Institutional Investing”, Wiley

Joseph Koshy (2006) "FDI in Retail sector" CopyrightC 2006, Joseph and Joseph Law Offices

Kamal Garg (2010), "Foreign Direct Investments in India”, Bharat Law House Private Limited

Nitin Kansal, (2009), "FDI and FII in India" Available on the Internet at (http://www.scribd.com/doc/17676898/FII-and-FDI-in-India)

\section{Copyrights}

Copyright for this article is retained by the author(s), with first publication rights granted to the journal. 